\title{
Effectiveness of Structured Teaching Programme on Knowledge Regarding Child Abuse among school children at a Selected school in Kanchipuram District
}

\author{
Authors \\ Dr T. Komalavalli M.Sc (N) Ph.D ${ }^{1}$, Prof. D.Kalaimani, M.Sc (N) ${ }^{2}$ \\ ${ }^{1}$ Principal, Karpagavinayaga College of Nursing Kacheepuram Dt \\ ${ }^{2}$ Karpagavinayaga College of Nursing Kacheepuram Dt
}

\begin{abstract}
Background of the study: Effectiveness of structured teaching programme on knowledge regarding child abuse among school children at a Selected school in kanchipuram district.

Objectives of the study

i) To assess the level of knowledge regarding child abuse among school children in pre and post test. ii) To evaluate the effectiveness of Structured Teaching Programme on knowledge regarding child abuse among school children. The Modified Imogene king's goal attainment theory was adopted to highlight the importance of child abuse among school children. A Pre experimental research design one group pre and post test was adopted for this study. A total of 50 children were selected by simple random sampling technique. Inferential statistics. The result revealed that there was a statistically significant differences between pre and post test knowledge score on child abuse among children $p<0.05$. Hence the structured teaching programme was effective among school children.

Keywords: Effectiveness, Structured teaching programme, knowledge and Child abuse.
\end{abstract}

\section{Introduction}

Child abuse is a social sickness has existed since the dawn of civilization, Sigmund Freud in a pare entitled, "a child is being beaten' described it as a universal subconscious wish to hurt the young. He communicated the parents were reluctant to talk about their sadistic feelings towards children and young people than they were about their sexual antics and fantasies.

According to WHO (2013) stated that international level of prevalence in child abuse and neglect was approximately 50500 children were at the risk of abuse right now. Nearly a quarter of young adults (24\%) experience sexual abuse by adult, one in 6 children aged 11-17 (16.5\%) have experience sexual abuse, one in 6 young adults $(16 \%)$ had been neglected. One in 14 young adults $(6.9 \%)$ experienced emotional abuse during childhood. Each year there are about 207754 victims of sexual assault.

\section{Statement of the Problem}

Effectiveness of Structured Teaching Programme on knowledge regarding child abuse among school children at a selected area in Kanchipuram District. 
Objectives of the Study

i) To assess the level of knowledge regarding child abuse among school children in pre and post test.

ii) To evaluate the effectiveness of Structured Teaching Programme on knowledge regarding child abuse among school children a brief description of research approach, research design, setting of the study, population, sample and criteria for sample section, sample technique, development of a tool, scoring procedure, pilot study, data collection procedure and data analysis.

\section{Research Approach}

A quantitative approach was used for this study.

\section{Research Design}

A Pre -Experimental design, one group pre and post test was used for this study to assess the effectiveness of structured teaching programme on knowledge regarding child abuse among school children at a selected school in Kanchipuram District.

\section{Research Design}

\begin{tabular}{|l|l|l|l|}
\hline Group & Pretest & Intervention & Post-test \\
\hline Study Group & $\mathrm{O}_{1}$ & $\mathrm{X}$ & $\mathrm{O}_{2}$ \\
\hline
\end{tabular}

\section{Variables}

Independent variable In this study, the independent variable was that structured teaching programme regarding child abuse among school children Dependent variable It refers to the knowledge regarding child abuse among school children.

Setting of the Study The study was conducted at pullipakam middle school in pullipakkam village at Kanchipuram district. This was situated $15 \mathrm{kms}$ away from Karpaga Vinayaga College of Nursing, Chinnkolambakkam, Kanchipuram District.

Sample It consisted of 50 school children in Kanchipuram district who fulfilled the inclusive criteria.

Sampling Technique A probability type of simple random sampling technique was adopted for the study.

\section{Description of the tool Score Interpretation}

Part I The numerical values were assigned for the demographic variables

Part II This consisted of 30 multiple choice questions and scores 1, 0 were given for right and wrong answer respectively. The total score were computed and categorized as follows:

\begin{tabular}{|l|c|c|}
\hline SCORES & CATEGORY & \% \\
\hline $15<$ & Inadequate knowledge & $<50 \%$ \\
\hline $16-23$ & $\begin{array}{c}\text { Moderately Adequate } \\
\text { knowledge }\end{array}$ & $51-75 \%$ \\
\hline $24-30$ & Adequate knowledge & $76-100 \%$ \\
\hline \multicolumn{3}{|c|}{ Total Score $=\mathbf{3 0}$} \\
\hline
\end{tabular}

\section{Distribution of level of knowledge on child abuse among school children in pre and post test}

\begin{tabular}{|l|l|c|c|c|c|}
\hline \multirow{2}{*}{ S.No. } & \multirow{2}{*}{ Level of knowledge } & \multicolumn{2}{|c|}{ Pre Test } & \multicolumn{2}{|c|}{ Post Test } \\
\cline { 3 - 6 } & & $\mathbf{N}$ & $(\boldsymbol{\%})$ & $\mathbf{N}$ & $(\boldsymbol{\%})$ \\
\hline 1. & Inadequate knowledge & 49 & 98 & 0 & 0 \\
\hline 2. & Moderately Adequate & 1 & 2 & 6 & 12 \\
\hline 3. & Adequate knowledge & 0 & 0 & 44 & 88 \\
\hline & Total & $\mathbf{5 0}$ & $\mathbf{1 0 0}$ & $\mathbf{5 0}$ & $\mathbf{1 0 0}$ \\
\hline
\end{tabular}

The above table disclosed that 49(98\%) study participants had inadequate knowledge whereas $1(2 \%)$ had moderately adequate knowledge in pre test. But in post test $6(12 \%)$ study participants had moderately adequate knowledge and $44(88 \%)$ had adequate knowledge. 


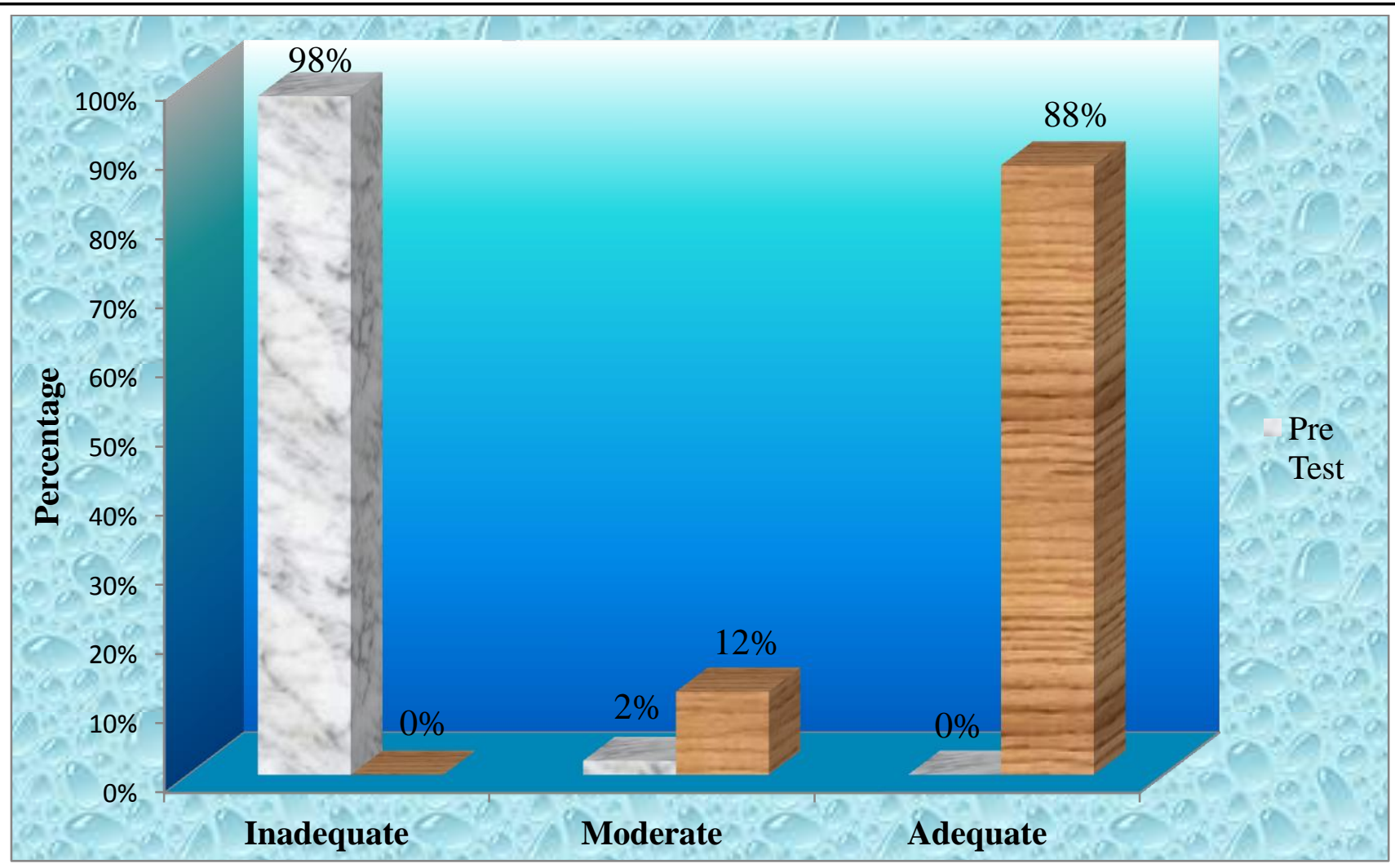

Fig. 12: Distribution of Pre and Post test score of Knowledge on Child Abuse Among school children

Comparison of pre and post test knowledge score on child abuse among school children

\begin{tabular}{|l|c|c|c|c|c|}
\hline S.No & Observation & Mean & SD & Paired "t" value & 'p' value \\
\hline 1. & Post test & 24.76 & 1.97 & \multirow{2}{*}{$37.68^{*}$} & \multirow{2}{*}{$\mathrm{P}=<0.05^{*}$} \\
\hline 2. & Pre test & 8.88 & 2.73 & & \\
\hline
\end{tabular}

\section{Significant at $\mathbf{p}<\mathbf{0 . 0 5 *}$}

The above table unveiled that there was a statistically significant difference between pre and post knowledge score on child abuse among study participants at level $\mathrm{p}<0.05^{*}$. The above data intervals also that the post test mean knowledge score- 24.76 was higher than the pre test mean knowledge score 8.88 among school children. The obtain 't' value was 37.68 significant at 0.05 level $(p<0.05)$. Hence the state hypothesis was *significant among which was statistically significant at level $\mathrm{P}<0.05$.

\section{Conclusion}

The study findings proved that the Structured Teaching Programme administered by the researcher was effective to increase the knowledge on the child abuse among school children

\section{Recommendations}

Based on the research findings the recommendations are as follows.

1) A similar study can be replicated on a large sample for wider generalization and also at different settings.

2) A similar study can be conducted to assess the knowledge and prevention among parents regarding child abuse.

3) A comparative study can be conducted among the rural and urban area of parents.

4) A descriptive study on assessing the knowledge and attitude of Anganwadi workers on child abuse and their practice can be done.

5) A structured teaching programme on child abuse can be prepared and given to the Anganwadi workers, so that they can impart knowledge to all areas of community. 
A structured teaching programme on child abuse can be prepared and given to the teachers and the parents'. so that they can impart knowledge to all school going children.

\section{Bibliography}

1. Ahuja Niraj. (2002). A short text book of psychiatry. (1st ed.). New Delhi: Jaypee Publishers.

2. Adele Pillitteri B. (2008.) Maternal and child health nursing, 3 rd edition. Philadelphia :Lippincott

3. Barbara Schoen Johnson. (2004). Psychiatric Mental Health Nursing. (4th ed.). Philadelphia: Lippincott.

4. Barker. (2003). Psychiatric and mental health Nursing. (1st ed.). London: Edward Arnold publisher.

5. Basavanthappa, B.T.(2007). Psychiatric Mental Health Nursing. (1st ed.). Newdelhi: Jaypee (P)Ltd.

6. Bhatia, M.S. Essential of Psychiatry, 2004. (4th ed.). Chennai: CBS publishers. \& Distributors. 